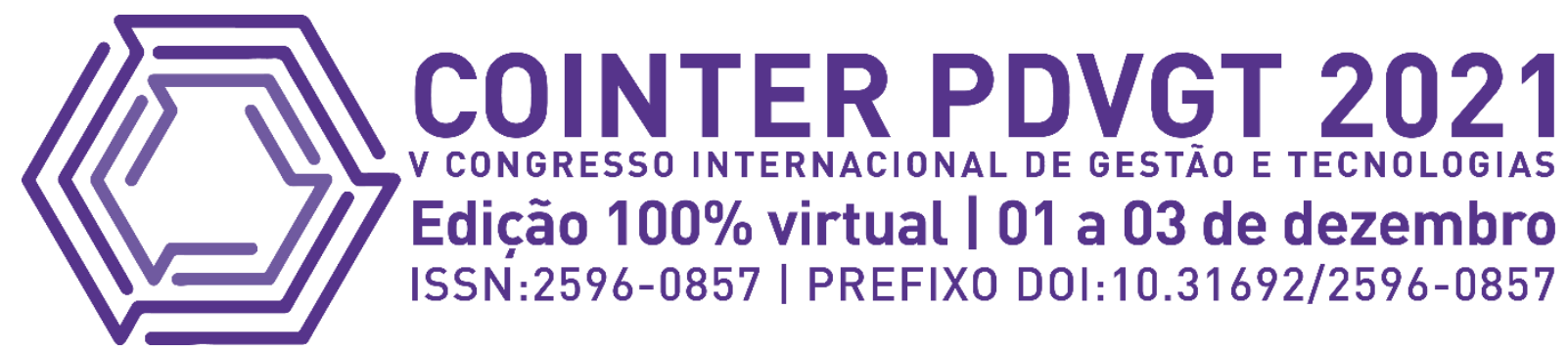

\title{
O SUPPLY CHAIN SOBRE O OLHAR DOS ESTUDANTES DE ADMINISTRAÇÃO DA ESCOLA TÉCNICA PERNAMBUCANA UNIDADE GOIANA-PE.
}

\section{LA CADENA DE SUMINISTRO SOBRE LAS PERSPECTIVAS DE LOS ALUMNOS DE ADMINISTRACIÓN DE LA ESCUELA TÉCNICA PERNAMBUCANA UNIDA EN GOIANA-PE.}

\section{THE SUPPLY CHAIN ABOUT THE PERSPECTIVES OF ADMINISTRATION STUDENTS OF THE PERNAMBUCANA TECHNICAL SCHOOL UNITED IN GOIANA-PE.}

\author{
Apresentação: Comunicação Oral \\ José Alisson de Oliveira ${ }^{1}$; Guilherme da Silva Andrade ${ }^{2}$; Ana Elisabeth de Brito Alves ${ }^{3}$;
}

DOI: https://doi.org/10.31692/2596-0857.VCOINTERPDVGT.0006

\section{RESUMO}

O artigo exibido a seguir discorrerá sobre o Supply Chain na visão dos estudantes do curso técnico de Administração da Escola Técnica Pernambucana da Unidade Goiana-PE com o estudo de caso "Cheiro no cangote" que viabiliza a fomentação da apresentação de uma solução para o caso com a aplicação dessa Cadeia de Abastecimento de forma eficaz. Refletindo que os estudantes estão sendo preparados pela instituição para o mercado de trabalho, o Professor ao aplicar o estudo de caso os coloca no papel de gestor e numa posição de tomada de decisão frente ao problema em questão e assim aplicar o Supply Chain que é a Cadeia de Abastecimento para ganhar vantagem competitiva e ter efeciência nessa logística que indubitavelmente acarretará em cliente satisfeito e valorizado, haja vista que esse deve ser o objetivo da empresa. O Supply Chain quando implantado de forma certa na organização é capaz de reduzir custos, aumentar a produção, satisfazer os clientes e ganhar grandes vantagens comparadas às empresas que não a utiliza ou usa de forma errônea. O trabalho de estudo de caso não possui o objetivo unicamente de exercitar os estudantes, mas também de simular uma realidade futura para que se tornem administradores diferenciados e com visão de mudança através dessa ferramenta, bem como de fazer valer os ensinamentos da disciplina e assim entregar ao mercado de trabalho, jovens adultos preparados para contribuir com a empresa no seu crescimento por meio de uma tão eficiente ferramenta. O momento em que os estudantes tiveram acesso ao estudo de caso foi logo pós uma aula sobre o supracitado assunto em seguida, ao concluir a atividade houve um debate sobre as diferentes opinões e respostas o que oportunizou outra bbemfeitoria, a escuta. Cada um ouviu a solução que os colegas apresentaram para o problema de estudo de caso e puderam notar as diferentes interpretações e diversas maneiras de aplicar o Supply Chain na empresa como solucionadora e mola de impulso para o crescimento da organização. O estudo de caso "Cheiro no cangote" foi aplicado aos

\footnotetext{
${ }^{1}$ José Alisson de Oliveira, Graduado em Administração pela Faculdade de Ciências de Timbaúba-FACET, alisson_oliveira0@ hotmail.com

${ }^{2}$ Graduado em Administração, Faculdade de Ciências de Timbaúba, guilhermeandrade14@hotmail.com

${ }^{3}$ Ana Elisabeth Brito: Mestre, SEED, Governo do Estado de PE, anabritoalves@gmail.com
} 
estudantes de curso técnico de Administração da ETP Unidade Goiana-PE pelo Professor Alisson Oliveira e com o apoio da Coordenação do curso. O intuito da proposta foi alcançado com sucesso já que os resultados apontaram a compreensão do problema e a amostra adequada de soluções, desta forma, os estudantes demonstraram capacidade para atuar na cadeia de abastecimento de toda e qualquer empresa.

Palavras-Chave: Supplay Chain, Administração, Estudantes, Competitivade.

\title{
RESUMEN
}

El artículo que se muestra a continuacíon abordará la Cadena de Suministro a la vista de los alumnos del curso técnico de Administración de la Escuela Técnica Pernambuco de la Unidad Goiana-PE, con el caso de estudio "Cheiro no cangote" que posibilita la promoción de la presentación de una solución para el caso aplicando esta Cadena de Suministro de manera efectiva. Reflejando que los estudiantes están siendo preparados por la institución para el mercado laboral, el profesor, al aplicar el caso de estudio, los ubica en el rol de administrador y en una posición de toma de decisiones frente al problema en cuestión y así aplicar la Cadena de Suministro que está Supply Chain para ganar ventaje competitiva y ser eficiente en esta logística que sin duda conducirá a un cliente satisfecho y valorado, dado que ese debe ser el objetivo de la empresa. La Supply Chain cuando se implementa de la manera correcta en la organización es capaz de reducir costos, incrementar la producción, satisfacer a los clientes y obtener grandes ventajas frente a empresas que no la usan o la usan incorrectamente. El trabajo de estudio de caso no solo tiene como objetivo ejercitar a los estudiantes, sino también simular una realidad futura para que se conviertan en administradores diferenciados con una visión de cambio a través de esta herramienta, así como hacer que las enseñanzas de la disciplina se apliquem y así se entreguen al público. Mercado laboral, jóvenes adultos preparados para contribuir al crecimiento de la empresa a través de una herramienta tan eficiente. El momento en que los estudiantes tuvieron acceso al caso de estudio fue justo después de una clase sobre el tema mencionado, luego, al finalizar la actividad, se produjo un debate sobre las diferentes opiniones y respuestas, lo que brindó la oportunidad de outra buena haciendo, escuchando. Cada uno escuchó la solución que sus colegas presentaron al problema del estudio de caso y pudieron notar las diferentes interpretaciones y diferentes formas de aplicar Supply Chain en la empresa como solucionador y trampolín para el crecimiento de la organización. El estudio de caso "Cheiro no cangote" fue aplicado a estudiantes del curso técnico de Administración de la Unidad ETP Goiana-PE por el profesor Alisson Oliveira y con el apoyo de la Coordinación del curso. El propósito de la propuesta se logró con éxito, ya que los resultados mostraron una comprensión del problema y una muestra adecuada de soluciones, por lo que los estudiantes demostraron la capacidad de actuar en la cadena de suministro de todas my cada una de las empresas.

Palabras Clave: Supplay Cadena, Administración, Estudiantes, Competitividad.

\begin{abstract}
The article shown below will discuss the Supply Chain in the view of the students of the technical course of Administration at the Pernambuco Technical School of the Goiana-PE Unit, with the case study "Cheiro no cangote" which enables the promotion of the presentation of a solution for the case by applying this Supply Chain effectively. Reflecting that students are being prepared by the institution for the labor market, the Professor, when applying the case study, places them in the role of manager and in a decision-making position facing the problem at hand thus apply the Supply Chain that is the Supply Chain to gain competitive advantage and be efficient in this logistics that will undoubtedly lead to a satisfied and valued customer, given that this should be the company's objective. The Supply Chain when implemented in the right way in the organization is able to reduce costs, increase production, satisfy customers and gain great advantages compared to companies that do not use it or use it wrongly. The case study work is not only intended to exercise students, but also to simulate a future reality so that they become differentiated administrators with a vision of change through this tool, as well as to make the teachings of the discipline apply and thus deliver to the job
\end{abstract}


market, young adults prepared to contribute to the company's growth through such an efficient tool. The moment in which the students had access to the case study was right after a class on the aforementioned subject, then at the end of the activity, there was a debate about the different opinions and answers, which provided an opportunity for another good-doing, listening. Each one listened to the solution that their colleagues presented to the case study problem and were able to notice the different interpretations and different ways to apply Supply Chain in the company as a solver and springboard for the organization's growth. The case study "Cheiro no cangote" was applied to students of the technical course of Administration at ETP Unit Goiana-PE by Profesor Alisson Oliveira and with the support of the course Coordination. The purpose of the proposal was successfully achieved, as the results showed an understanding of the problem and an adequate sample of solutions, thus, the students demonstrated the ability to act in the supply chain of any and all companies.

Keywords: Supplay Chain, Administration, Students, Competitiveness.

\section{INTRODUÇÃO}

O Supplay Chain ou Gestão da Cadeia de Abastecimento foi lecionado aos alunos do Curso Técnico de Administração e Logística da Escola Técnica Pernambucana ETP na Unidade Goiana-PE e extraído através desse trabalho de pesquisa o olhar que os estudantes tem sobre a importância dessa cadeia dentro da empresa. Suas percepções foram entendidas a partir do estudo de caso que fora aplicado em sala de aula que desafiou-os a ajir como gestores e aplicar a Cadeia de Abastecimento de acordo com os relatos ficticios da atividade apresentada.

Para que futuros gestores adentrem no mercado de trabalho é importante que saiam com entendimento de aplicar a ferramenta que dará possibilidades de vantagens competitivas e que com os avanços atuais é imprescindível sua prática. Dessa maneira, o trabalho em questão levanta e enaltece através de uma sólida base teórica com o olhar de diversos autores e pesquisadores e também com a visão dos estudantes de um curso técnico que corrobora a relevância dessa temática que sem sombras de dúvidas é uma propulsora do sucesso empresarial tendo em vista seu objetivo final é o cliente.

Segundo (Paura, 2012,p.19) Apud Mondêgo Jéssica 2017, “A busca pela satisfação do cliente é algo essencial para a vida de uma empresa" (PAURA, 2012, p. 19) com essa busca por deixar o cliente feliz com sua compra é que foi trabalhado com os estudantes da Escola Técnica Pernambucana na Unidade Goiana-PE para que sua formação seja consciente e responsável frente a um mercado altamente competitivo, porém , eles tendo uma vantagem com esse intensivo da Supply Chain. É muito cabivél que os alunos indaguem sobre como irão atuar dentro da empresa. Quais os melhores caminhos? Como aplicar com excelência o Supply Chain da cadeia da empresa? Essas e outras perguntas faz compreender que a Cadeia de Abastecimento é capaz de satisfazer os clientes, reduzir custos e alavancar na frente dentre outras empresas. 
Este trabalho de pesquisa tem a visão de contribuir na discussão dessa temática, aplicando aos estudantes de nível técnico que estão prestes a serem introduzidos nas organizações e que consequentemente terão a missão de colaborar para o crescimento organizacional da instituição fazendo com que os estudantes se coloquem na pele de um gestor por meio do estudo de caso que foi aplicado a eles. O estudo de caso "Cheiro no Cangote" de autoria do Professor Alisson Oliveira narra uma história fictícia, porém embasada nos estudos da disciplina, para que os alunos ao analisarem os erros apontados dessem a solução para o caso e assim fosse despertada a liderança o comportamento dos mesmos na missão de aplicar o Supply Chain, ou seja, introduzir a Cadeia de Abastecimento na empresa e sanar os problemas dela com visão de crescimento e satisafação dos consumidores.

O estudo de caso "Cheiro no Cangote" aplicado aos estudantes do curso técnico de Administração e Logística da ETP Unidade Goiana-PE, foi fomentado após aula de Gestão da Cadeia de Abastecimento e oportunizou aos alunos praticar mesmo que na teoria quais comportamentos teriam na organização frente ao problema apresenatdo, esta simulação é causadora de um teste de ações que sem dúvidas precisarão ter como profissionais e com esse trabalho compreender a importância do Supply Chain.

\section{FUNDAMENTAÇÃO TEÓRICA}

A Cadeia de Suprimentos é abrangente e tem suas ramificações presentes em diversas áreas seja de forma direta ou indireta, contribuindo com a eficácia desde sua origem de fabricação de um produto até o consumidor final. Ela não inclui apenas fabricantes e fornecedores, como também transportadores, depósitos, varejistas e os próprios clientes, assim, essa cadeia envolve todos esses estágios que é ocasianado com o pedido do cliente. Seu dinamismo requer bastantes informações entre as partes do processo já que abrange um fluxo contínuo de produtos e recursos financeiros entre as segmentações e estes interagem com cada elo da Cadeia de Abastecimento.

De acordo o Global Supply Chain Fórum (GSCF) apud Correa Rinaldi [2006?];

"SCM é a integração dos processos de negócios desde o usuário final até os fornecedores originais (primários) que providenciam produtos, serviços, e informações que adicionam valor para os clientes e stakeholders."

Desta forma, o Supply Chain integra todos os processos do ínicio ao fim do pedido do cliente com o controle eficiente em cada etapa para fins de obter um sistema de confecção e entrega com excelência dando satisfação ao consumidor final. É importante frisar que em todo 
essse processo com as váriais etapas da cadeia a informação é uma base fundamental que é repleta de vantagem siginificativa possuida pelo varejo que é pode ser o doferencial a tantos outros participantes da Cadeia de Abastecimento.

\section{1-Processos de uma cadeia de abastecimento}

A administração da Cadeia de Abastecimento é uma junção de operações que são realizadas para conceder uma melhor integração e uma gestão eficiente de todos os parâmetros estabelecidos em toda rede agregando os processos de transportes, estoques, custo e outros que estão presentes não somente nos fornecedores, como também na própria organização e nos consumidores. É correro afirmar que a Cadeia de Abastecimento ou Supply Chain engloba não só os pontos direta ou indiretamente do atendimento de pedidos dos clientes, mas também os fornecedores, fabricantes, transportadores, depósitos e varejistas.

O produto certo na quantidade certa está atrelada a uma gestão adequada da cadeia que possibilita a interação de uma produção otimizada que vai de encontro com a logística em sua excelência. Com a redução dos custos no itinerário da cadeia e com o cuidado as exigências do cliente o Supply Chain vai alcançando seus obejtivos, já que se os clientes estiverem sendo atendidos com eficácia, entregando o que o consumidor quer e no preço e nas circunstâncias que o referido almeja significa dizer que tudo está se encaminhando para uma cadeia de sucesso. A gerência não é uma atividade de nível fácil, porém fica mais seguro quando existe controle sobre todos os processos e para que isso ocorra com equidade é muito importante que tenha ciclos acompanhados como um termômetro averiguando a eficiência da logística.

\subsection{Ciclo de pedido ao Cliente}

Os clientes possuem suas necessidades, seus desejos e depositam expectativas nos produtos que buscam, nisso o ciclo de pedido ao cliente precisa atender aos pedidos com o minímo custo nos processos da cadeia e as etapas dos fornecedores.

Na Apostila do Professor Givaldo Torres [2020?], é definida algumas atividades que incluem o pedido do cliente.

Preparação: A preparação de pedidos refere-se às atividades de obtenção das informações necessárias sobre os produtos ou serviços desejados e, formalmente, à requisição dos produtos a serem comprados.

Transmissão: Envolve a transferência do pedido requisitado do seu ponto de origem ao lugar no qual a entrada de pedido pode ser manuseada.

Entrada: A entrada de pedidos foi beneficiada grandemente pelos melhoramentos tecnológicos, como códigos de barra, leitores ópticos e computadores.

Preenchimento: O preenchimento do pedido é representado pelas atividades 
físicas exigidas para adquirir os itens por meio da retirada do estoque, da produção ou da compra; empacotar itens para embarque; programar o embarque para entrega e para preparar a documentação do embarque;

Comunicação sobre a situação do pedido: Esta é a atividade final de processamento de pedido e assegura um bom serviço prestado ao cliente. Professor GIVALDO TORRES [2020?].

Com essas atividades fica nítido que há controle e com isso os resultados positivos que se espera da boa aplicação da cadeia de abastecimento virá com preparação, transmissão, entrada, preenchimento e comuniçao de pedido.

\subsection{Ciclo de reabastecimento}

No ciclo de reabastecimento acontece o processo no qual a empresa se relaciona com os seus fornecedores, ou seja, devendo definir as formas de se relacionar com quem fornece seus produtos tendo como objetivo obter uma parceria de equilibrio. Assim sendo, o ciclo de reabastecimento conta com os processos de Acionar o pedido do varejista, emitir o pedido do varejista, atender ao pedido do varejista, receber o pedido pelo mesmo e o pedido que o vareista faz para reabastecer os estoques para atender uma demanda vindoura.

\subsection{Ciclo de Fabricação}

No ciclo de fabricação a produção é realizada de acordo com as quantidades de produtos que são exigidos, logo, as demandas são enviadas para o centro de fabricação e esse percurso pode ser definido pelo tempo transcorrido até o endereçamento ao consumidor final ou nos armazéns que recebem os produtos prontos.

\subsection{Ciclo de Suprimentos}

Já no ciclo de suprimentos há a compreensão de que nele integre todos os processos que são fundamentais na garantia de uma fabricação eficiente e eficaz com os materiais para a produção e sem haver atrasos na confecção dos mesmos.

\section{Puxado (Pull) e Empurrado (Push)}

No Supply Chain com seu ciclo de suprimentos há a garantia na disponibilidade dos produtos de fabricação que é quando a empresa assegura o não atraso de seus produtos e com planejamento e controle dentro dos processos de Pull (Puxado) quando a partir dos pedidos dos clientes inicia a confecção dos pedidos e Push (Empurrado) que é quando é feito primeiramente o produto para que depois haja a saída dele.

Com esse sistema dentro da cadeia percebem-se vantagens e desvantagens que os 
gestores devem se ater para evitar prejuízos em seus negócios, tendo em vista que quando o processo se denomina puxado significa dizer que a fabricação do produto ocorre depois que o cliente faz seu pedido, ou seja, é a partir de uma demanda e com essa forma de produzir a empresa pode evitar um grande estoque de produtos que consequentemente evita muitos custos e reduz filas de produção. Já no processo da cadeia que ocorre o empurrado a fabricação se antecede e acaba produzindo sem que haja pedidos, ou seja, fabrica-se sem demanda alguma e assim pode acarretar em grande quantidade de estoque do produto e filas no processo de fabricação o que pode ser um gargalo para organização. Vale frisar que tudo precisa ser controlado e equilibrado já que a falta de produtos pode também ser a causadora de perda de venda ou cliente. Portanto, a empresa necessita de equilibrio e estudo sobre seu público alvo, períodos sazonais e interesse dos clientes a respeito dos seus produtos para deiar faltar como também não gerar grandes quantidades estocadas.

\section{A Integração do Sistema de Informações da Empresa (ERP)}

A sigla ERP significa Enterprise Resource Planning que em Português Sistema de Planejamento Empresarial. Essa ferramenta integra todos os processos com planejamento e faz todo o diferencial da organização demandando todo instrumento para o controle que ajudarão das tomadas de decisções. O ERP é um sistema de software que integra os dados de uma empresa num único sistema, bem como suas informações e melhoramento da comunicação interna da organização com os setores e partes que a compõe promovendo efetividade e prodtividade com o obejtivo de aperfeiçoar a rotina dos departamentos estratégicos da instituição.

O Enterprise Resource Planning (ERP) possui um maior volume de dados para as insitiuições que indubitavelmente são cada vez mais necessitadas de TI e que assim acabam acumulando muita informação, com isso é imprescindível estratégias de arquivamento para proporcionar previsões de mercado com precisão e acertividade nas decisões da empresa. Um dos sistemas é o "Big Data" que gerencia e cria um quadro capaz de melhorar as elaborações do negócio.

No Supply Chain, ou seja, numa Cadeia de Abastecimento é de suma importância a implantação de um sistema que integre as partes envolvidadas de uma empresa, ainda mais quando esta obejtiva permanecer competitiva no mercado na atualidade que está tomada pela informação. O maior intuíto do sistema integrado ou ERP é oferecer controle e amparo para os processos operacionais e sua existência possibilita uma evolução inteligente no planejamento da instituição quando simulam cenários de negócios, potencializando a 
produção e sua distribuição. Vale frisar que estes sistemas integrados foram projetados para contribuir com as organizações no mercado competitivo dando uma vatagem frente a outras instituições na gestão dos seus processos que são por vezes, críticos. As aplicações destas ferramentas permitem uma resposta rápida às expectativas dos clientes e as realidades do mercado já que envolve a produção, compras, distribuição e manutenção.

Para Bertaglia Paulo (2006);

O sistema ERP é integrado, e o acesso às diferentes informações é possível, sem a necessidade de reconciliação ou checagem de dados. Ele também elimina os eventuais conflitos existentes entre os vários departamentos e divisões. Os dados da organização são integrados em uma única base. Bertaglia Paulo (2006).

A evolução de cada sistema vai se aperfeiçoando em consonância com as necessidades que vão surgindo das empresas. Esse sistema conta com uma eficiência que através da redução de tempo dá agilidade as atividades além de banir os exercícios surperfluos e o melhoramento nos controles. Há empresaas que reduzem suas entregas de meses para semanas e torna seus estoques mais reduzidos o que afeta a diminuição dos custos da cadeia logística.

\section{Custos Logísticos}

Segundo Ballou (2001) apud Correa Rinaldi [2006?], o custo logístico é uma somatória dos custos dos elementos-chaves (elos) dessa cadeia, por exemplo, o custo de transporte, o custo de armazenagem, processamento de pedido etc. Os custos de uma cadeia de logística se dão a partir das execuções da organização e suas atividades são divididas em duas categorias: diferenciação competitiva e reduçao de custos. A diferenciação tem uma percepção mais simples e seu retorno é entregue em forma de satsiafação do consumidor e consequentemente o volume aumentado. Já o aspecto de redução de custo não é tão fácil assom já que os clientes estão cada vez mais exigentes e ofertando melhores níveis de serviço, porém nem sempre estão dispostos a pagar o preço por tal produto.

De acordo com o Instituto dos Contadores Gerenciais - IMA (1992) Apud Torres Givaldo [2020?] Os custos logísticos são os custos de planejar, implementar e controlar todo o inventário de entrada (inboud), em processo e de saída (outbound), desde o ponto de origem até o ponto de consumo. Há o Custo de Armazenagem que estuda a forma correta o armazenamento adequado de estoques físicos, neles a empresa tem segurança de armazenar com eficácia seus produtos e manter seu estoque com Armazenagem Pública que são as taxas cobradas por unidades estocadas, o espaço ocupado ou a movimentação da mesma e os custos 
com Armazenagem Prédio próprio ou alugado que envolve os gastos de aluguel, instalações elétricas, hidráulicas, água, luz, energia, IPTU e etc.

Segundo Medeiros (1999) Apud Mondêgo Jéssica 2017;

\begin{abstract}
"Os sistemas contábeis oferecem informações pobres para avaliar os custos dos produtos dos modernos fabricantes. Tais sistemas adequadamente 28 relacionam custos contra receitas em um nível macro da contabilidade, mas eles sistematicamente distorcem os custos no nível micro dos produtos individuais. A distorção surge por causa da forma que os contadores das empresas de manufatura tradicionalmente alocam os custos indiretos (overhead) aos produtos" (MEDEIROS, 1999, p. 4). "Com o objetivo de tomar decisões sensatas referentes aos produtos que eles vendem, gerentes precisam saber quanto seus produtos custam. $\mathrm{O}$ projeto de produtos, decisão sobre lançamento de novos produtos, e a quantidade de esforço despendido ao tentar vender um dado produto ou linha de produto será influenciada pela antecipação do custo e da lucratividade. Contrariamente, se a lucratividade do produto der sinais de queda, a proposta de descontinuidade surgirá. Os custos dos produtos desempenham um importante papel na fixação de preços" (MEDEIROS, 1999, p. 4).
\end{abstract}

Assim sendo, os custos possuem essa viabilidade para uma tomada de decisão acertiva dentro da empresa, por isso é tão fundamental que os gestores planejem seus custos e controle dentro da Cadeia de Abastecimento.

\title{
5. Nível de Serviço
}

De acordo com Bertaglia Paulo (2009) as organizações estão preocupadas com as necessidades dos clientes, e voltadas para elas, utilizam o conceito de "serviço ao cliente" para avaliar o desempenho do sistema de controle de estoques. O quantitativo de itens disponiveis e itens demandados deve ser controlado e cuidadosamente observado para uma satisfação ao consumidor final com o atendimento ao pedido fazendo uma relação entre essas quantidades, haja vista que muitas instituições adcionam o conceito de tempo que é justamente comparar o nível de atendimento ao cliente em termos de quantidade, bem como o produto e sua disponibilidade para a data na qual foi requerida. Essa peculiaridade é necessária para conseguir a satisfação do cliente e para que haja o atendimento a demanda que é feita diretamente dos consumidores. Há ainda a fundamental observância quanto à disponibilidade dos produtos para atender aos clientes sem que esses não sejam frustrados quando os procurar. Para Bertaglia Paulo (2009) a procura de um produto e a sua ausência em uma gôndola pode levar o consumidor a comprar um produto concorrente, o que significa uma venda perdida. Bertaglia quer dizer em sua afirmação que as empresas devem se preocupar também com seus estoques e como eles podem ser gerador de satisfação ou 
insatisfação, grandes estoques sem planejamento podem acarretar em riscos ou prejuízos e falta dele pode resultar na perda de uma venda ao cliente.

O OTIF (on time in full) é o que representa ao dinamismo da organização em atender à demanda incluído no tempo acordado e na quantidade combinada. Com isso o Supply Chain é identificado o quanto pode ser eficiente, tendo em vista não ser um indicador casual e na verdade não pode ser isolado. Para que uma empresa atenda os seus clientes e mantenha em nível superior o OTIF muitos processos e subprocessos precisam ser exercitados em seu início nas vendas, visitando as qualificações dos fornecedores, passeando pela produção com eficiência com as distribuições e as funções administrativas dentro de todo o processo da Cadeia de Abastecimento.

Com o Nível de Serviço ao Cliente há a Acurácia de Estoque que é embasada na relação entre a quantidade física que existe no armazém e as que estão sistematizadas no controle da empresa. Esse controle pode ser realizado nos mais avançados sistemas que são incumbidos de integrar os processos, as partes envolvidas que é o Enterprise Resources Planning (ERP) conforme já vimos sobre essa ferramenta anteriormente nesse artigo.

\section{METODOLOGIA}

Essa é caracterizada como explicativa, haja vista que demanda amplia o fator conhecimento referente ao conteúdo estudado e a temática levantada. Para concluir os objetivos do trabalho aqui descrito, a pesquisa classifica-se como prática de natureza científica e bibliográfica tendo caráter qualitativo e obtendo como metodologia aplicada usouse o estudo de caso "Cheiro no Cangote" para extrair dos estudantes do curso de Administração e Logística da Escola Técnica Pernambucana - ETP unidade Goiana-PE

Lakatos e Marconi (1985, p. 81), destacam que o método é aquilo que é percebido como um conjunto de atividades organizadas em um sistema lógico a fim de alcançar-se um objetivo. Desta maneira, o assunto sobre Supply Chain foi estudado com eles em sala de aula na disciplina da Gestão de Cadeia de Abastecimento e após a exposição do conteúdo foi elaborado pelo Professor o estudo de caso e entregue aos estudantes para que desse a solução ao problema.

Diante do exposto, os estudantes da ETP de Goiana-PE na qual teve a prática dessa atividade em sala de aula vivenciaram uma discussão em roda de debate onde cada um leu e refletiu sobre sua resposta, ou seja, sua solução para o caso apresentado se colocando como gestor e aplicando a cadeia de abastecimento com planejamento e controle para fins de 
PRINCIPAL, et al.

alcançar com objetivos da empresa com a satisfação dos clientes.

\section{RESULTADOS E DISCUSSÃO}

O artigo aqui exposto teve sua aplicação após a proposta da discussão da temática aos estudantes de nível técnico do curso de Administração e Logística da Escola Técnica Pernambucana na Unidade Goiana-PE, no qual o professor durante a aula da disciplina Gestão da Cadeia de Abastecimento aplicou o estudo de caso "Cheiro no Cangote" uma história fictícia que foi elaborada de acordo com o conteúdo par fins de apresentar uma problemática aos alunos e incitá-los a resolver aplicando a cadeia de abastecimento, ou seja, o Supply Chain. Assim, eles através dessa simulação compreendiam ainda mais a importância dessa ferramenta para a empresa e se coloca no papel do profissinal, afinal de contas estão sendo preparados para isso.

Ao término da realização de respostas sobre o estudo de caso, os estudantes em uma roda de debate leram suas propostas de resolução do caso e obviamente ouviram as dos colegas para a prática também da escuta e da boa comunicação que deve ter dentro do Supply Chain.

O trabalho de pesquisa em sala de aula demonstra o comprometimento dos estudantes, sua interpretação do caso, capacidade de resolver problema, identificação da importância do Supply Chain para alavancar positivamente a empresa e a escuta que é tão importante entre os membros do ambiente profissional que nesse caso foi representado pelos colegas de sala.

O Estudo de Caso aplicado foi o exposto abaixo:

A empresa "Cheiro no cangote" está há 20 anos no mercado de produção e venda de perfumaria. Destarte, a empresa cresceu na última década de maneira relevante. Seu faturamento aumentou três vezes mais, tendo nos dias atuais um quadro de funcionários com aproximadamente 100 colaboradores. A diretoria é composta pela família do fundador, a família Cunha e desta forma suas decisões são tomadas em conjunto por seus membros da direção e com a participação dos gestores das áreas envolvidas.

Anualmente a equipe gestora com os colaboradores de níveis gerenciais se reúnem para traçar os planos da empresa "Cheiro no cangote" e construir sua logística desde sua fabricação até o cliente final. Contudo, não existe um acompanhamento do que fora planejado nem tampouco a Gestão da Cadeia de Abastecimento que engloba além dos fabricantes, fornecedores, os transportadores, depósitos, varejistas e clientes, não havendo o cumprimento da quantidade certa, 
bem como não há controle nos custos ao longo da Cadeia. A falta de termômetro para aferição da
eficiência do processo logístico vem comprometendo o faturamento da empresa "Cheio no
cangote". Vale frisar que os demais funcionários da parte operacional não tomam conhecimento do
planejamento, muito menos são ouvidos. Os não alcances das metas traçadas nestas avaliações
anuais estão acarretando na demissão de gerentes.
Mesmo com seu crescimento na última década, a empresa "Cheiro no cangote" não é tão lucrativa
quanto a outras de seu segmento que investe na Cadeia de Abastecimento. Sua logística de
Fornecimento, Suprimentos, Produção, Distribuição e Clientes é falha.
Pede-se: Considerando esse cenário, você está sendo contratado para gerir o departamento de
logística da empresa "Cheiro no cangote". A sua missão é propor a implantação e o controle sobre
toda a cadeia desde sua fabricação até o cliente final, reduzindo os custos, obtendo os materiais
disponíveis e sem atrasos para o consumidor final.

Fonte: Autoria própria (2021)

Portanto, após o uso de estudo didático compreende-se que os estudantes atenderam as expectativas de compreensão da importância do Supply Chain e se colocaram de forma exitosa no papel de um gestor tomando as decisões com planejamento e controle, focando nos resultados da organização que é a satisfação dos seus clientes por meio de uma cadeia de abastecimento eficiente.

\section{CONCLUSÕES}

Este artigo possuiu o intuito de afirmar a relevância do tema abordado e da diferença positiva que toda e qualquer empresa passa a ter quando introduz em sua logística o Supply Chain, ou seja, a Cadeia de Abastecimento. Essa afirmação aconteceu através do olhar dos estudantes do curso técnico que com a aula da disciplina aprenderam suas atribuições e fundamentabilidade dentro da organização.

Houve o objetivo também de propor essa discussão e fazer ser conhecida essa ferramenta ainda não muito vista pelos estudantes e no mercado atual, podendo dessa maneira contribuir com o conhecimento e apontar os caminhos para uma boa aplicação desse processo tão eficiente. Essa maneira didática de aplicar um problema através de um conto fictício e com o tema extrovertido "Cheiro no cangote" fez com que os estudantes resolvam o problema em questão de forma divertida, leve, porém sem retirar o compromisso e responsabilidade da entrega da solução e isso ocorreu com êxito. 
Foto 1: Momento de Discussão

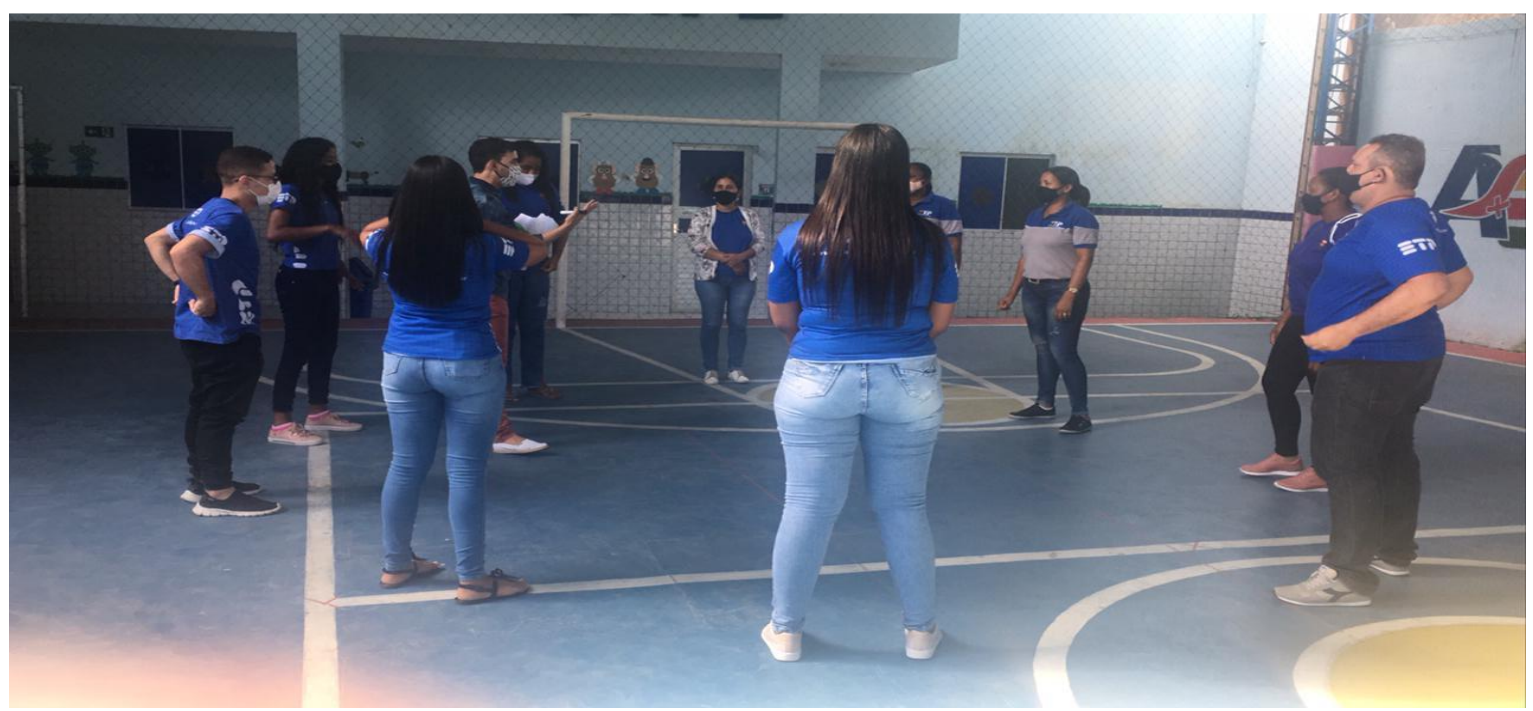

Fonte: Acervo pessoal - 2021

Assim sendo, o estudo de caso aplicado trouxe grandes e bons resultados para os estudantes, coordenação e instituição de ensino que além de apresentar o assunto tem a oportunidade de simular o comportamento de futuros admintradores, gestores, empresários que certamente colcoarão em prática o uso dessa ferramenta.

\section{Foto 2: Comportamento dos futuros Administradores}

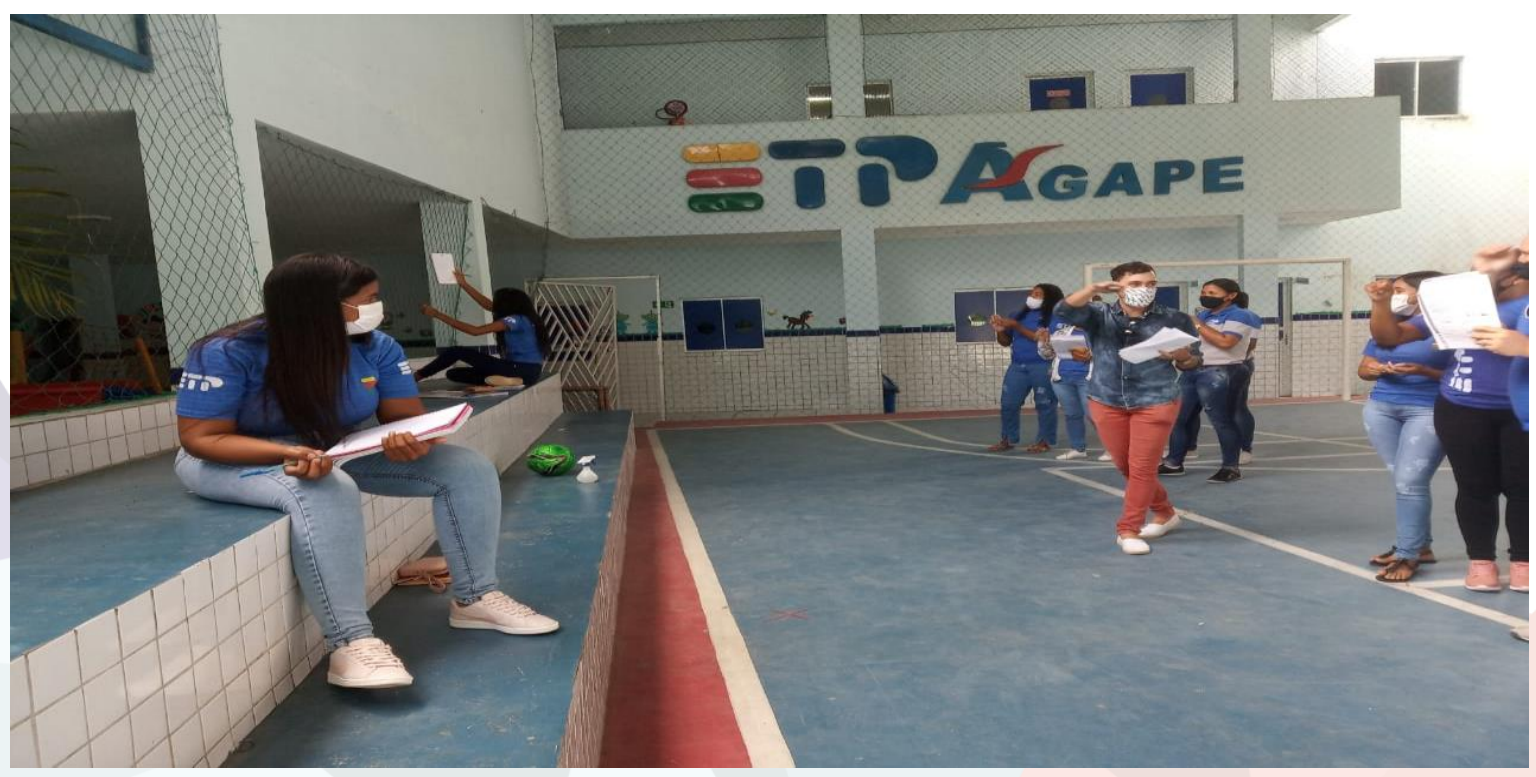

Fonte: Acervo pessoal - 2021

Somado a isso, fica nítido que o Supply Chain faz toda a diferena e abre vantagens competitivas gigantes no mercado de trabalho frente a outras empresas que não a utiliza ou usa de forma errada, sem planejamento nem controle. É basilar aplicá-la de forma 
responsável, organizada e buscando a satisafão dos clientes em todo o processo da cadeia de Abasteciento e isso ficou claro nas respostas particpativas de cada estudante incluso nesse trabalho de pesquisa amplo e facinante.

\section{REFERÊNCIAS}

GIVALDO, Torres Apostila: Gestão da Cadeia de Abastecimento. Professor - ETP, Goiana-PE.

MEDEIROS, Edmilson Soares de. Metodologia para Implementação do Sistema de Custeio Baseado em Atividades (ABC) nos Serviços Logísticos da Indústria de Exploração e Produção de Petróleo: Aplicação no Provedor de Transporte do Órgão de Exploração \& Produção da Petrobrás na Bacia de Campos. Dissertação submetida à Universidade Federal de Santa Catarina para Obtenção de Título de Mestre em Engenharia de Produção. Florianópolis, 1999.

MONDEGO, Jéssica Linhares. CUSTOS LOGÍSTICOS: INSTRUMENTO DE MELHORIA, Dissertação de Mestrado apresentada ao Programa de Pós-graduação em Engenharia de Produção, COPPE, da Universidade Federal do Rio de Janeiro. 2017.

PAURA, Glávio Leal. Fundamentos da Logística. Rede e-Tec Brasil. Instituto Federal de Educação, Ciência e Tecnologia - Educação a Distância. Paraná. Curitiba, 2012.

SITE: https://www.mxm.com.br/blog/4-tendencias-que-irao-guiar-o-futuro-dos-sistemas-degestao-erp/ 